
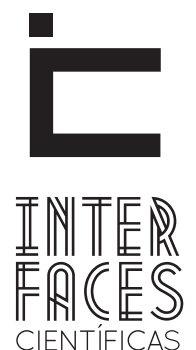

EDUCAÇÃO

ISSN IMPRESSO 2316-333X

ISSN ELETRÔNICO 2316-3828

DOI 10.17564/2316-3828.2016v4n3p81-90

\title{
O SERVIÇO DE PSICOLOGIA E OS TESTES: PREPARANDO EM LABORATÓRIO AS TRANSFORMAÇÕES NO ENSINO DE MATEMÁTICA DOS ANOS INICIAIS
}

Nara Vilma Lima Pinheiro ${ }^{1}$
Wagner Rodrigues Valente ${ }^{2}$

\section{RESUMO}

Esse texto trata de resultados parciais da pesquisa, em desenvolvimento, sobre experiências realizadas com testes mentais e de escolaridade, aplicadas em escolas primárias de São Paulo. Os testes utilizados eram apropriações de modelos estrangeiros e adaptados ao contexto brasileiro pelo Serviço de Psicologia Aplicada na década de 1930. Trata-se de um tempo em que a pedagogia buscava o status de ciência e se consolidou com o movimento de aplicação de testes psicológicos e pedagógicos no ambiente escolar. A investigação busca responder algumas questões: em meio a tantos testes estrangeiros, quais foram os escolhidos para aferir as habilidades aritméticas na escola primária paulista? Que habilidades aritméticas seriam testadas? Como fonte de pesquisa utilizar-se-á atas do Serviço de Psicologia Aplicada.

\section{PALAVRAS-CHAVE}

Pedagogia Científica. Aritmética. Testes Pedagógicos. 


\section{ABSTRACT}

This paper comes to partial search results, in development, about experiences with mental tests and pedagogical tests applied in primary schools of São Paulo. The tests used were appropriations of foreign models and adapted to the brazilian context by the Serviço de Psicologia Aplicada in the 1930s. This is a time when the pedagogy sought the status of science and consolidated with the application of psychological tests and movement teaching in the school environment. The investigation seeks to answer some questions: among many foreign tests, which were chosen to measure arithmetic skills in the state primary school? Which arithmetic skills would be tested? As a research source will be used documents of Serviço de Psicologia Aplicada.

\section{KEYWORDS}

Scientific Pedagogy. Arithmetic. Pedagogical Tests.

\section{RESUMEN}

Este trabajo se ocupa de los resultados de búsqueda parciales en desarrollo sobre experiencias con las pruebas y la educación mental, aplicados en las escuelas primarias de. Las pruebas utilizadas fueron créditos de modelos extranjeros y adaptados al contexto brasileño por el Servicio de Psicología Aplicada en la década de 1930. Este es un momento en que la pedagogía buscó el estado de la ciencia y se consolidó con la aplicación de pruebas psicológicas y movimiento la enseñanza en el ámbito escolar. La investigación busca responder algunas preguntas: entre muchas pruebas extranjeras, que fueron elegidos para medir las habilidades aritméticas en la escuela primaria estatal? Que las habilidades aritméticas se pondrá a prueba? Como fuente de investigación se utilizará minutos del Departamento de Psicología Aplicada.

\section{PALABRAS CLAVE}

Pedagogía Científica. Aritmética. Pruebas Pedagógicas. 


\section{CONSIDERAÇÕES PRELIMINARES}

No Brasil, a ideia de conduzir a educação de modo mais científico, menos empírico e voluntarioso adentra os espaços escolares a partir da criação de laboratórios para aplicação prática e teórica dos fundamentos da psicologia experimental. Serão eles a darem referência para o trato das questões educativas de modo a serem considerados os resultados obtidos pela psicologia experimental com aferição estatística. Como exemplo disso, tem-se em São Paulo a constituição, em 1914, do Laboratório de Pedagogia Experimental, no Gabinete de Psicologia e Antropologia Pedagógica, anexo à Escola Normal Secundária de São Paulo, para a ampliação dos estudos teóricos e práticos da nova pedagogia (CARVALHO, 2000).

As pesquisas desenvolvidas neste laboratório buscavam "subsidiar a ação educacional, preocupados muito mais com a classificação das crianças do que com a busca de meios mais efetivos para a melhoria do processo de ensino e aprendizagem" (ANTUNES, 2007, p. 79). Sob a direção de Ugo Pizzoli ${ }^{1}$, neste espaço, foram ministrados cursos teóricos e práticos de Psicologia, orientação de pesquisas e elaboração da carteira biográfica escolar, para ser adotada nas escolas públicas paulistas (ANTUNES, 2007, p. 79).

Os conteúdos tratados por Pizzoli em seus cursos e as atividades desenvolvidas no laboratório sempre estiveram mais ligadas à medida das funções psicológicas, sendo o fenômeno perceptivo o mais estudado, o que contribuiu para "o conhecimento científico que a Pedagogia reclamava como base de sustentação e que the permitiram proclamar-se Pedagogia Científica" (ANTUNES, 2007, p. 80. Grifo nosso).

Ainda em 1914, foi publicado o livro O Laboratório de Pedagogia Experimental, o qual relatava detalhes das atividades desenvolvidas no laboratório. Inicial-

\footnotetext{
1. Médico italiano e pedagogista.
}

mente o livro trazia uma palestra de Oscar Thompson intitulada $O$ futuro da Pedagogia é científico. 0 texto privilegiava a Psicologia como base científica para a Pedagogia, justificando assim, a criação da cadeira de Psicologia Experimental Aplicada à Educação e do Laboratório de Pedagogia Experimental.

Na década de 1920 os laboratórios perdem o protagonismo e entra em cena a era dos testes coletivos. Considerava-se que esses instrumentos psicológicos permitiam medir de modo mais econômico, uma vez que não precisavam de "aparelhamento complicado, podíamos mesmo dizer, sem aparelhamento algum, que habilita todo mestre a tentar a experimentação psicológica, por si só, e a observar por ela, melhormente, seus discípulos" (LOURENÇO FILHO, 1929, p. 5-6).

É nessa década que surgem os primeiros profissionais da Educação ligados à vaga pedagógica escolanovista, fundamentada em boa medida na psicologia da base experimental, a qual "deveria subsidiar as transformações da escola; as relações professor e aluno, o processo de ensino-aprendizagem, a modernização metodológica, a organização das classes, o conhecimento e o respeito ao desenvolvimento da criança" (ANTUNES, 2007, p. 84). Assim a pedagogia considerada científica se "consolidou pela medida, pelos tests" onde a experimentação desempenhou papel fundamental. "Em específico, a utilização dos tests no âmbito escolar foi 'a face mais visível' da emergência da pedagogia científica" (VALENTE, 2013, p. 1).

Com a inserção dos testes psicológicos no ambiente de ensino a psicologia aplicada à educação estabeleceu-se definitivamente na cultura escolar da época, adquirindo prestígio na instrução pública (MONARCHA, 2001). No âmbito paulista, sob o governo de Getúlio Vargas, Lourenço Filho assumiu a direção da Instrução Pública e iniciou a reforma do ensino que adotava os princípios da Escola Nova. 
As iniciativas de Lourenço Filho visavam "à substituição das práticas de natureza empírica e rotineira, tanto no âmbito do magistério quanto no da administração escolar, por procedimentos científicos" (MONARCHA, 2001, p. 35). Nesse sentido criou um espaço técnico-pedagógico separado da administração. Novas seções especializadas foram criadas: inspeção médico escolar, biblioteca pedagógica central, museu da criança, inspeção escolar e serviço de assistência técnica. Dentre essas seções têm destaque dois serviços inéditos: o museu da criança - o qual tinha por finalidade o estudo objetivo da criança, com bases na Antropometria, Psicometria, Arte Infantil, Pedagogia Experimental e Patologia Infantil - e o Serviço de Assistência Técnica - o qual deveria ser entregue a um grupo de especialistas reconhecidos por sua competência, destinados ao estudo dos problemas de aperfeiçoamento do ensino e de seu controle (MONARCHA, 2001).

Com o passar do tempo, apenas os serviços de assistência técnica "ganharam autonomia e assumiram a dinâmica de instâncias normativas do aparelho e do trabalho escolar" (MONARCHA, 2001, p. 36). Em especial, o Serviço de Psicologia Aplicada (SPA) encarregado da organização de classes seletivas, para o $1^{\circ}$ ano dos grupos escolares da capital paulista, e aplicação de testes mentais e pedagógicos.

\section{AS ATIVIDADES DO SERVIÇO DE PSICOLOGIA APLICADA [SPA]}

O SPA foi criado em 1931, subordinado à Secretaria de Educação e Saúde Pública do Estado de São Paulo e instalado nas dependências da Escola Normal da Praça, durante a gestão de Lourenço Filho na Diretoria Geral da Instrução Pública de São Paulo. Posteriormente, o SPA passou a denominar-se Laboratório de Psicologia Educacional (BAPTISTA, 2001).

O serviço subdividia-se em quatro seções principais: medidas mentais, medidas do trabalho escolar, orientação, estatística. Funcionou durante 10 anos, servindo dentre outras coisas como local de "desenvolvimento de atividades práticas para os alunos estagiários" (BAPTISTA, 2001, p. 338). Contava com autonomia no cotidiano escolar, encarregando-se da organização das classes seletivas do $1^{\circ}$ ano dos grupos escolares e da aplicação dos testes mentais e pedagógicos. Inicialmente, o SPA divulgou as primeiras ideias de Psicologia Educacional por meio de "cursos de capacitação dos professores, palestras sobre testes mentais e escolares, estudos de adaptação dos testes Binet-Simon e Dearbon para escolares paulistas" (MONARCHA, 2009, p. 9).

Lourenço Filho, juntamente com Noemy Silveira, realizou pesquisas sobre medidas psicológicas, medidas do trabalho escolar, orientação escolar e profissional. Noemy Silveira foi uma das responsáveis pela aplicação dos testes elaborados por Lourenço Filho para a verificação da maturidade necessária à aprendizagem da técnica da leitura e da escrita em grupos escolares paulistas. Esses testes, mais tarde, possibilitaram a escrita da obra publicada por Lourenço Filho sob o título Testes $A B C$ para verificação da maturidade necessária à aprendizagem da leitura e da escrita.

A primeira reunião do SPA ocorreu em 20 de julho de 1931, a qual tratou de discutir a importância da estatística escolar, considerada "uma veemente e eloqüente prova, é por ela que se demonstram, ao mestre de outrora empírico e livre de pesquisas, certas grandes verdades" (REGISTRO DAS REUNIÕES..., 1931 [1 ${ }^{\text {a }}$ reunião]). Nessa reunião ficaram estabelecidas as primeiras iniciativas de se trabalhar com os testes mentais e de escolaridade, e de se levar a consciência técnica ao âmbito escolar. 0 primeiro teste de inteligência a ser experimentado com crianças brasileiras foi a Escala de Binet e a preparação da técnica do teste coletivo de inteligência de Dearbon. Ainda na primeira reunião ficou estabelecido que os membros do SPA apresentassem, no decorrer das reuniões, depoimentos das pesquisas realizadas e ficha de leituras de obras referências. Durante as reuniões de 1931 a 1932 foram apresentados os fichamentos das obras listadas no Quadro 1: 
Quadro 1 - Relação de obras referências para discussão nas reuniões do SPA

\begin{tabular}{|c|c|}
\hline Títulos & Autor \\
\hline $\begin{array}{l}\text { Pscychologia de l'ntelli- } \\
\text { gence }\end{array}$ & Édouard Claparède \\
\hline $\begin{array}{l}\text { Texto sobre o valor dos tes- } \\
\text { ts como medida do traba- } \\
\text { lho escolar, }\end{array}$ & $\begin{array}{l}\text { Boletim oficial do Minis- } \\
\text { tério da Instrução Públi- } \\
\text { ca de Lisboa }\end{array}$ \\
\hline Diagnóstico de aptidões & Édouard Claparède \\
\hline Psicologia Moderna & $\begin{array}{l}\text { extraído da obra de } \\
\text { Claparede A educação } \\
\text { Funcional }\end{array}$ \\
\hline $\begin{array}{l}\text { A história da Psicologia In- } \\
\text { fantil }\end{array}$ & Não identificado. \\
\hline O Barulho das Cidades & $\begin{array}{l}\text { Boletin de Higiene, maio } \\
\text { de } 1931 \text { - Departamen- } \\
\text { to de Saúde Pública de } \\
\text { Nova Yorque }\end{array}$ \\
\hline $\begin{array}{l}\text { As refeições nas estações } \\
\text { quentes }\end{array}$ & $\begin{array}{l}\text { Doris McGray, Nigéria, } \\
\text { julho de } 1931\end{array}$ \\
\hline $\begin{array}{l}\text { A estatística e o pensa- } \\
\text { mento }\end{array}$ & $\begin{array}{l}\text { Bckingham, União Pan } \\
\text { Americana }\end{array}$ \\
\hline $\begin{array}{l}\text { Les modernes ideés sur les } \\
\text { enfants }\end{array}$ & Alfred Binet \\
\hline $\begin{array}{l}\text { Meaning and Nature of } \\
\text { teaching }\end{array}$ & Stebel and Morecheart \\
\hline $\begin{array}{l}\text { Education for a Changing } \\
\text { Civilization }\end{array}$ & Kilpatrick \\
\hline $\begin{array}{l}\text { O Método científico - in- } \\
\text { troducção a la ciência }\end{array}$ & Não identificado. \\
\hline $\begin{array}{l}\text { A conduta nos grupos de } \\
\text { discussão }\end{array}$ & Spence Watson \\
\hline Organização da Educação & Comenius \\
\hline $\begin{array}{l}\text { Quadro Integral da Peda- } \\
\text { gogia }\end{array}$ & $\begin{array}{l}\text { Extraído de Tristão e } \\
\text { Athayde }\end{array}$ \\
\hline $\begin{array}{l}\text { La medida objectiva del } \\
\text { Trabajo escolar }\end{array}$ & Alejandro Gali \\
\hline
\end{tabular}

Fonte: Quadro elaborado pelos autores com base nas Atas das reuniões do SPA no período de 1931 a 1932.
Como se percebe tratavam-se de obras estrangeiras de intelectuais defensores da Escola Ativa e de uma pedagogia científica, tendo como principal instrumento psicológico os testes. Dessa relação de obras, em particular, nos interessa La Medida Objectiva del Trabajo Escolar, por se tratar de um estudo sobre testes pedagógicos, sobretudo de aritmética.

O fichamento de algumas dessas obras aponta para uma estratégia ${ }^{2}$ de convencimento dos professores já que os textos escolhidos se referiam aos benefícios dos testes aplicados no cotidiano de ensino e a importância da estatística escolar. Em uma das reuniões a professora Eulália de Siqueira, responsável pela Seção de Medida Objetiva do Trabalho Escolar, apontou para o valor dos testes como medida escolar e a importância da estatística para "apreciar cada um no seu justo valor, mostrando a cada um, verdades que não podem e não devem ser ignoradas" (REGISTRO DAS REUNIÕES..., 1931 [3a reunião]).

$\mathrm{Na}$ adaptação de testes coletivos de inteligência para o contexto brasileiro, outras escalas, além da Dearbon, foram utilizadas para a estandardização em escolas brasileiras. Nas reuniões do SPA foi discutido um plano de ação dos testes coletivos de inteligência de Ballard, a partir da comparação das revisões de Helena Antipoff em Minas Gerais, de Bueno de Andrade no Rio de Janeiro, de Ulisses Pernambuco em Recife e a de Decroly - versão fiel a de Ballard. Da comparação concluiu-se que a versão de Bueno de Andrade era a que mais se aproximava da original.

De modo geral, a Seção de Medidas Mentais trazia os resultados estatísticos das pesquisas realizadas nos grupos escolares da Capital paulista com os

2. Neste ponto cabe uma referência a conceitos importantes mobilizados por este estudo. Este é o caso do termo "estratégia". Ele deve ser considerado a partir dos estudos de Roger Chartier. Diz o autor: "As percepções do social não são de forma alguma discursos neutros: produzem estratégias e práticas (sociais, escolares, políticas) que tendem a impor uma autoridade à custa de outros, por elas menosprezados, a legitimar um projeto reformador ou a justificar, para os próprios indivíduos, as suas escolhas e condutas" (Chartier, 1990, p. 17). 
testes $A B C$. Segundo Ata da reunião, os resultados estatísticos de aplicação dos testes $A B C$ permitiam concluir que seria possível: dar um tratamento especial a cada criança pelo conhecimento de suas necessidades; diminuir a porcentagem de reprovação; um julgamento equitativo do mérito dos professores. Entretanto, consideravam que os resultados estatísticos não eram suficientes e se fazia necessário ouvir os professores. Foram elaboradas algumas questões para os professores responderem:

1) Que resultados esperam os professores quanto a promoção?

2) Acham os professores vantagens de ensinar a um grupo homogêneo?

3) Acham os professores que realmente houve seleção?

4) Notaram os professores maior aproveitamento por parte das crianças? (REGISTRO DAS REUNIÕES..., 1931 [6 ${ }^{\text {a }}$ reunião], [s.p.]).

Ao analisar as respostas dadas a essas questões é possível dizer que se tratava de uma estratégia de convencimento sobre os benefícios dos testes $A B C$ e, principalmente, validar perante os professores os dados estatísticos obtidos.

No decorrer de 1931 a 1932 as discussões nas reuniões do SPA referiam-se a organização de quadros de especificação. Ao que tudo indica tratava-se de um plano de ação para a estandardização de testes, onde seria necessário definir a habilidade que seria avaliada, o objetivo dos testes e a maneira de se avaliar. 0 quadro de especificação era uma maneira de assegurar que os resultados visados seriam avaliados (REGISTRO DAS REUNIÕES..., 1931-1932).

As experimentações realizadas no SPA, sob orientação de Noemy Silveira, serviram como exemplos "para quaisquer outras iniciativas no Sistema Educacional no sentido de preparar pessoal para executá -las devidamente" (MONARCHA, 2009, p. 9). Exemplo disso foram as experiências realizadas no curso primário anexo a Escola Normal de Casa Branca, no interior paulista. Em 1936 essa escola organizou um ciclo de palestras sobre estatística e elaboração de testes para uso nas classes primárias. Nessas palestras os professores aprenderam tópicos de estatística básica e como elaborar um quadro de especificações.

Nesse caso, o quadro de especificações deveria ser elaborado a partir de questões que melhor se adaptavam aos testes e que foram aplicadas durante o ensino, desprezando aquelas "de pouco ou nenhum valor" (FONSECA, 1936, p. 56). Na execução do quadro era recomendado que se utilizasse a lei da probabilidade, onde $25 \%$ de questões fossem fáceis, 50\% médias e $25 \%$ difíceis. Assim os conteúdos dos testes seriam determinados pelos professores, baseados nas aulas ministradas no curso primário.

Em se tratando da Aritmética o serviço de testes trabalhou com a Escala Courtis, fez um estudo das provas de Alejando Gali e aplicou uma bateria de testes elaborada pelo professor José Ferraz Campos. Infelizmente, até o momento, não foram encontradas maiores informações sobre os testes elaborados por esse professor. Dessa forma, no próximo item trataremos apenas da Escala Courtis e das provas de Alejandro Gali.

\section{AS ESCALAS DE CÁLCULO DE COURTIS E ALEJANDRO GALI}

Segundo o Relatório dos trabalhos da seção de medidas mentais, em novembro de 1931 iniciou-se a aplicação da Escala de Cálculo no Grupo EscolarRodrigues Alves. Ao que tudo indica, tratava-se de aplicação da Escala de Cálculo Courtis ${ }^{3}$. Essa bateria de testes era constituída por 48 cartões. 0 primeiro cartão era constituído por 72 operações de adição envolvendo os números naturais de 0 a 9 . Na Figura 1 têm-se onze exemplos da operação de adição utilizada nos testes de Courtis.

3. Também encontramos referência a essa escala no manual Tests, de Medeiros e Albuquerque - trata-se do primeiro manual publicado no Brasil sobre a temática - e no manual Os tests e a reorganização escolar, de Isaías Alves. 


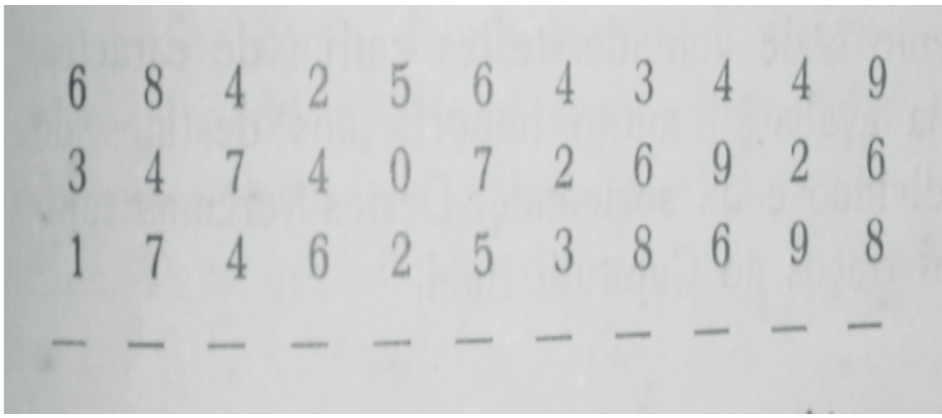

Fonte: Alves (1930, p. 149).

O tempo de execução do primeiro cartão variava de acordo com o grau de ensino, por exemplo, se os alunos pertencessem ao $6^{\circ}$ grau o tempo de realização era de 4 minutos, se pertencessem ao $8^{\circ}$ grau deveria executar em 3 minutos, se fossem do $4^{\circ}$ grau inferior o tempo era de 6 minutos e 25 segundos. As operações eram realizadas em papel transparente, estendido sobre o cartão. Os resultados das operações ficavam no verso do cartão para o aluno conferir. Todas as demais operações elementares eram realizadas "com grande variedade de exemplos, não havendo, em mais de 600 cálculos, uma só conta de dividir em que o divisor tenha mais de quatro algarismos" (ALVES, 1930, p. 150). A escala Courtis era considerada útil como diagnóstico de cada uma das operações.

Em fevereiro de 1932 teve início o estudo detalhado das provas objetivas de Alejandro Gali, a partir da obra La medida objectiva del trabajo escolar, a fim de verificar quais eram aplicáveis ao contexto brasileiro. Nesse estudo Gali (1931, p. 267) defendia que um bom mestre necessitava de uma consciência técnica para coordenar o ritmo do trabalho escolar com "os progressos da técnica e com as necessidades da vida moderna".

Esta consciência técnica permitiria por meio de testes e de programas elaborados experimentalmente verificar se o conteúdo que se desejava ensinar estava de acordo com a idade da criança e se os processos empregados adaptavam-se à psicologia infantil e, mais do que isto, se o interesse que se pretendia despertar era vital ou apenas um passatempo. Assim era necessário que o professor abandonasse as observações empiristas e adotasse a consciência técnica, pois a valorização quantitativa autorizava o diagnóstico e ofereceria a base para indicação de um tratamento determinado. No caso da Aritmética haveria:

\section{[...] uma série de exercícios cientificamente ordenados e valorizados, cujo nível de execução fornece, automatica- mente, a medida desejada. Em sua forma externa, estes exercícios são como as séries ordinárias de problemas es- colares, porém, cada um deles tem uma significação pre- cisa relativa a idade e ao grau. (GALI, 1931, p. 293-294).}

A ideia era de que o aluno resolvesse os exercícios sem perceber que se tratava de um teste, seria uma espécie de trabalho escolar. Acreditava-se que esta maneira diferenciada de aplicação dos testes contribuiria para uma "valorização do programa escolar, que dê por si mesma a avaliação da criança sem necessidade de recorrer a medidas especiais" (GALI, 1931, p. 294). Na obra La medida objetiva del trabajo escolar, Gali (1929) se recusava a apresentar modelos de escalas sistematizados e rígidos, se preocupava em orientar os leitores na elaboração de operações de modo a cumprir critérios da Escala de Operações e da Escala de problemas ${ }^{4}$. Segue exemplo de Escala de Operações para $1^{\mathrm{a}}, 2^{\mathrm{a}}, 3^{\mathrm{a}}, 4^{\mathrm{a}}, 5^{\mathrm{a}}$ e $6^{\mathrm{a}}$ série:

4. Tratava-se de escalas dividas em faixas etárias ( 3 anos e meio até 13 anos de idade) e as habilidades aritméticas esperadas. 
Figura 2 - La Medida Objectiva del Trabajo Escolar

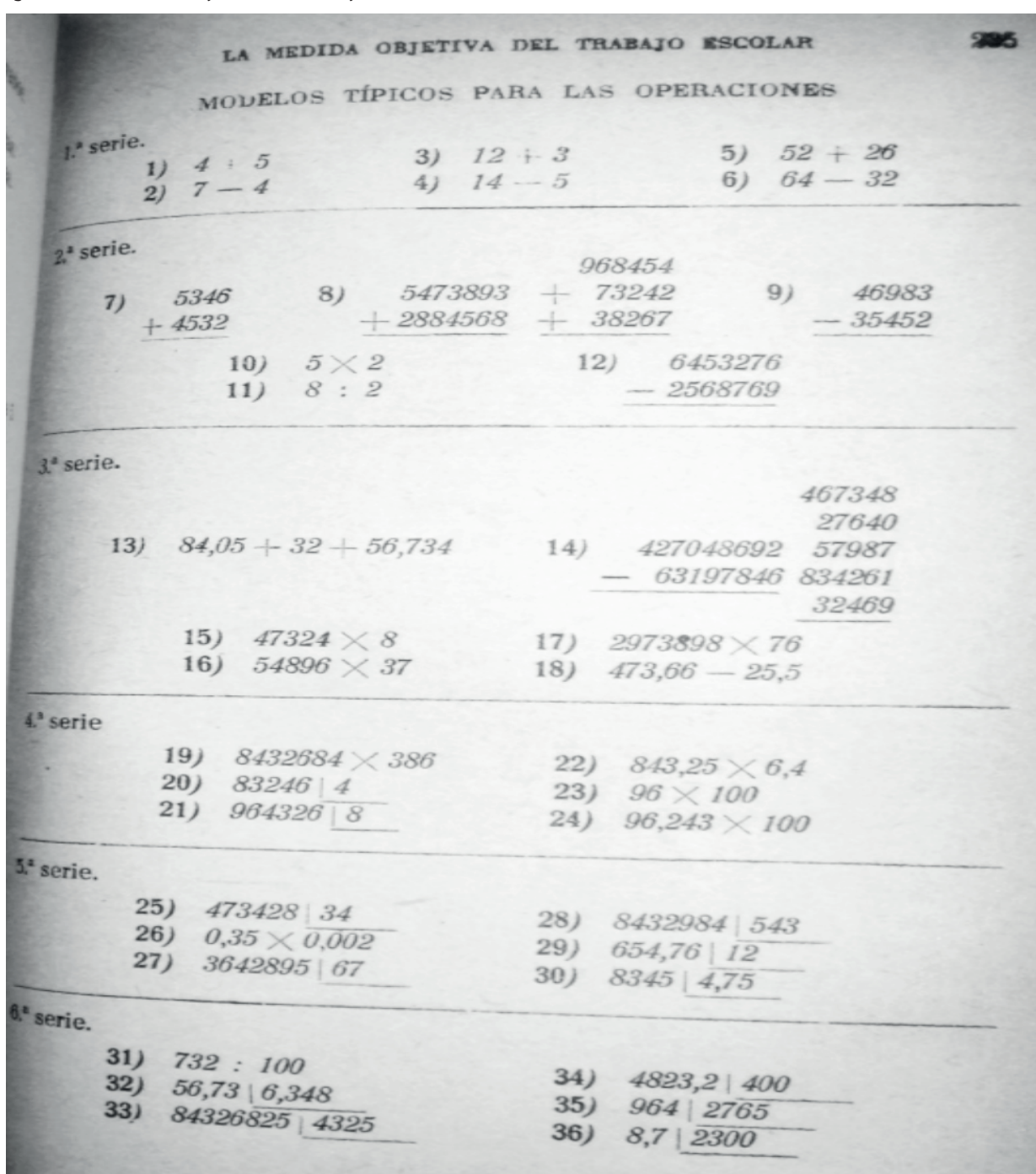

Fonte: Gali (1929, p. 235).

Diferentemente de outros autores que consideravam uma operação correta apenas se o resultado estivesse certo, Gali (1929) dava preferência ao mecanismo, o que justificava a tolerância aos erros de cálculo. Segue exemplo da operação de adição:

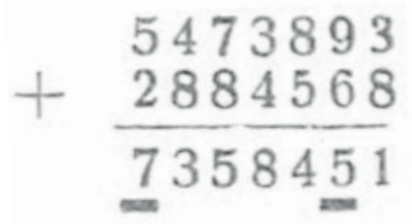


A resolução dessa operação foi bem avaliada por Gali (1929), pois das sete somas parciais cinco estavam corretas. 0 critério de correção considerava bem avaliada uma operação "cuando la mitad más uno de los casos específicos que la motivan han sido resultos, siempre que los casos que pudiéramos llamar neutros lo estén em la misma propoción" (GALI, 1929, p. 238).

\section{CONSIDERAÇÕES FINAIS}

Em tempos da chamada Pedagogia Científica assiste-se ao movimento dos laboratórios de psicologia como verdadeiros centros de pesquisa sobre a realidade escolar e os modos de condução do processo educacional. Desses laboratórios virão os resultados aferidos em ambiente controlado, com avaliação estatística, ditando o que será preferível utilizar nas escolas. Um novo momento segue-se a essa importação de orientações vindas dos laboratórios: a utilização dos testes estandardizados. Menos custoso seria o processo e estaria ao alcance das mãos do professores. Mas, para que isso ocorresse seria preciso haver todo um trabalho de escolha, de testagens prévias, de modo a oferecer para as escolas os instrumentos por meio dos quais a pedagogia se faria mais e mais científica: os testes pedagógicos e mentais.

A proposta inicial deste artigo foi identificar quais foram os testes escolhidos para aferir as habilidades aritméticas na escola primária paulista e tentar verificar quais habilidades aritméticas seriam testadas. Estando o estudo em fase inicial de desenvolvimento, é possível dizer que o serviço de medidas do SPA adotou, num primeiro momento, como modelo os estudos de Courtis para o contexto brasileiro. Ao que tudo indica a intenção era medir as habilidades de efetuar as técnicas operatórias do cálculo. Pela discussão presente nas atas das reuniões do SPA, o trabalho de adaptação de material estrangeiro foi desenvolvido a partir de muita reflexão e discussão entre todos os membros do serviço de medidas.
Quanto aos estudos de Gali, por se tratar de um intelectual que incentivava a elaboração de testes por professores, acreditamos que tal estudo serviu como referência para as discussões sobre a elaboração de testes pelo professor José Ferraz Campos.

Neste ponto cabe perguntar: Como os professores da escola primária se apropriaram desses instrumentos? As experiências desenvolvidas pelo SPA se conformaram em práticas pedagógicas? Ou ainda, como os resultados das experiências com testes pedagógicos afetaram o programa de matemática da escola primária? Estas são questões que o estágio inicial da pesquisa deixa em aberto para desenvolvimento futuro.

\section{REFERÊNCIAS}

\section{ALVES, I. Os testes e a reorganização escolar.}

Prefácio de Anísio Spinola Teixeira. Bahia: Nova Gráfica, 1930.

ANTUNES, M. A. M. A psicologia no Brasil: leitura histórica sobre sua constituição. 5.ed. São Paulo: Educ, 1998, 2007.

BAPTISTA, M. T. D. da S. Noemy da Silveira Rudolfer (1902 - 1988). In: CAMPOS, R. H. de F (Org.). Dicionário biográfico da psicologia no Brasil. Rio de janeiro: Imago, 2001.

CARVALho, M. M. C. de. Modernidade pedagógica e modelos de formação docente. São Paulo Perspec. [online]. 2000, v.14, n.1, p.111-120. ISSN 0102-8839. Disponível em: <http://www.scielo.br/scielo.php?script=sci arttext\&pid=S0102-88392000000100013\#back1>. Acesso em: 21 set. 2013.

CHARTIER, R. A história cultural - entre práticas e representações. Rio de Janeiro: Bertrand Brasil S. A., 1990. 
FONSECA, Maria Ari. Relatório das atividades desenvolvidas durante 0 ano de 1936, no curso primário anexo à Escola Normal de Casa Branca. São Paulo: Casa Branca, 1936.

\section{GALI, A. La medida objectiva del trabajo escolar.}

Tradução Juan Comas Camps. Madrid: M. Aguilar, 1929.

GALI, A. Conceito de medida do trabalho escolar. In: Introdução aos estudos dos Tests. Escola Nova, v.II, n.3-4, São Paulo, mar-abr. 1931. p.260-303.

LOURENÇO FILHO, M. B. Prefácio do tradutor. In: BINET, A.; SIMON, T. Testes para a medida do desenvolvimento da inteligência. São Paulo: Melhoramentos, 1929.

MEDEIROS; ALBUQUERQUE. Tests: introdução ao estudo dos meios científicos de julgar a inteligência e aplicação dos alunos. Rio de Janeiro: Livraria Francisco Alves, 1937.

\section{MONARCHA, C. Lourenço Filho e a organização da psicologia aplicada à educação: São Paulo,}

1922 - 1933. Brasília: Instituto Nacional de Estudos e Pesquisas Educacionais, 2001.

MONARCHA, C. Notas sobre a Institucionalização da Psicologia em São Paulo: o serviço de Psicologia Aplicada (1930 - 1938). Boletim Academia Paulista de Psicologia - Ano XXIX, n.1, enero-junio, 2009. p.7-15.

REGISTRO DAS REUNIÕES para pesquisas e estudos dos membros da Assistência Técnica de Psicologia Aplicada da Diretoria Geral de Ensino, 01/07/1931 a 14/03/1932. Acervo: Centro de Memória do Instituto de Psicologia da USP.

REGISTRO DE FREQUÊNCIA e Diário dos trabalhos da Secção de Medidas do Serviço de Psicologia Aplicada da Diretoria Geral do ensino - Instituto Pedagógico de São Paulo. 13 de outubro 1931 - 18 de janeiro de 1932. Acervo: Centro de Memória do Instituto de Psicologia da USP.

VALENTE, W. R. A Era dos Tests e a Pedagogia Científica: um tema para pesquisas na Educação Matemática.

Revista Acta Scientiae, v.16, 2014. p.11-26. 